\title{
MAATALOUDEN TULO VALTER LINDBERGIN TUTKIMUKSESSA "SUOMEN KANSANTULO VUOSINA 1926-1938".
}

\author{
Rurik Pihkala.
}

Saapunut 19. VI. 1946.

Painosta ilmestyi syksyllä erittäin mielenkiintoinen, yllämainitulla otsikolla varustettu tutkimus. ${ }^{1}$ Siinä selvitetään Suomen kansantuloa vuosina 1926--1938 tavalla, johon on syytä kiinnittää huomiota.

Kansantulo on jaettu seuraaviin alaryhmiin: maatalous ja sen sivuelinkeinot, kalastus ja metsästys, metsätalous, teollisuus, käsityö ja kotiteollisuus, rakennustoiminta, kuljetus ja liikenne, kauppa ja siihen liittyvät elinkeinot, pysyväisten kulutushyödykkeiden käyttö, vapaat ammatit, kotitảloustyö ja julkinen toiminta. Kustakin alaryhmästä lasketaan ensin bruttotulo, josta sen jälkeen, kun on suoritettu ryhmään kuuluvat vastaavat vähennykset, saadaan lopullinen ns. puhtotulo.

Tutkimuksen alkuosassa (luvuissa I-V) käsitellään niitä yleisiä perusteita, käsitteitä, menetelmiä ja hintoja, joiden mukaan tällaisia tutkimuksia yleensä on suoritettava, ja sitten selvitetään vielä yksityiskohtaisesti, miten kukin laskelma tässä tutkimuksessa on laadittu. Tämä osa teoksesta on erittäin mielenkiintoinen ja ansiokas ja osoittaa, kuinka vakavasti tutkija on tehtävänsä ottanut. Menetelmät, joita on käytetty, on perinpohjaisesti selostettu, ja menetelmien valinta on yleensä osunut oikeaan. Määritelmien suhteen on kuitenkin huomautettava, että tulo- ja tuotto-käsitteet eiväț ole selvät. Se käy ilmi esim. siitä (siv. 146), että käsitteestä puhtotulo on käytetty nimitystä nettotuotto (Reinertrag), vaikka Reinertrag on vallan toista kuin tri Lindbergin puhtotulo. Vaikka menetelmiin nähden ei olekaan muistuttamista ja laskelmațkin yleensä on suoritettu sillä tavalla, että lukija tulee vakuuttuneeksi niiden paikkansapitävyydestä, niin kuitenkin täytyy valittaen tulla siihen tulokseen, että mikäli asia koskee maataloutta, eivät tutkimuksen tulokset, vaikka menetelmät hyväksytäänkin, ole käsitykseni mukaan oikeat. Olen sitä mieltä, että maatalouden kansantaloudellinen tulo kokonaisuudessaan ja sen osat, kasvinviljely- ja kotieläintulo, molemmat ovat virheellisesti lasketut, kuitenkin niin, että kotieläintulon ja kasvinviljelytulon suhde on suunnilleen oikea sen vuoksi, että osapuilleen samansuuruinen virhe on kummassakin sillä tavalla, että virheet suhdetta määritettäessä tasoittavat toisensa. Kun maa-

1 Valter Lindberg: Suomen kansantulo vuosina 1926-1938. Suomen Pankin Suhdannetutkimusosaston Julkaisuja, B: 1, 1943 
talouden asiantuntijana tätä tutkimusta laadittaessa on ollut tri WiLLANDT, en voi sanoa, kuinka paljon näistä virheistä on vastuussa tri Lindberg ja kuinka paljon tri Willandt; kuitenkin epäilemättä molemmat ovat näistä tuloksista vastuussa.

Kun esitän tällaisen väitteen tuloksien virheellisyydestä, on velvollisuuteni lähteä tarkemmin perustelemaan sitä.

Kansantaloudellinen tulo maataloudessa voidaan määrittää joko käyttäen, kuten tri Lindberg on tehnyt, ns. reaalimenetelmää tai myös laskemalla se esimerkiksi seuraavan prof. E. LAURIN kaavan mukaan ${ }^{1}$ :

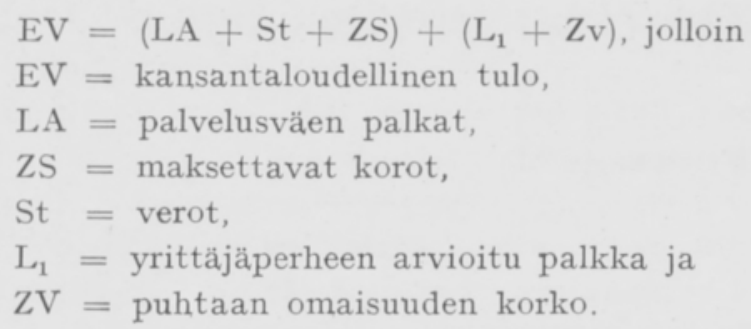

Tämä kaava voidaan johtaa myös sellaiseen muotoon, että kansantaloudellinen tulo $(\mathrm{EV})$ on = palvelusväelle maksetut palkat ja yrittäjäperheen arvioitu palkka, siis yleensä palkat ja tähän lisättynä verot ja puhdastuotto. Kun Suomessa puhdastuotto-käsitteeseen sisällytetään maatalouden verot, voidaan maatalouden kansantaloudellinen tulo meillä siis laskea siten, että palkkoihin lisätään maatalouden puhdastuotto (ns. verotettava puhdastuotto). ${ }^{2}$ Kansantuloa laskettaessa on muistettava, että tulos on joka tapauksessa summittainen ja pitää siis paikkansa vain ylimalkaisena. Mutta jos menettelytavat ovat oikeat, täytyy eri tavoilla saatujen summittaistenkin laskelmien käydä suunnilleen yhteen.

Maataloudessa on vuosittain käytetty n. 188 miljoonaa muunnettua miehen työpäivää. Jos muunnetun työpäivän hinnaksi esim. v. 1938 arvioidaan $35 \mathrm{mk}$ päivältä, tulee tästä jo yli 5,5 miljardia markkaa. ${ }^{3}$ Tällöin herää epäilys, ettei tri Lindbergin tulos, joka ei minään vuonna nouse maatalouden kohdalla yli 6 miljardin, voi olla oikea, koska maatalouden palkkoihin pitäisi vielä lisätä puhdastuotto kansantaloudellisen tulon saamiseksi.

Tri Lindberg on saanut tämän tuloksen, kuten -edellä mainittiin, ns, reaalimenetelmää käyttäen. Hän on sitä mieltä, että on uskallettua esittää varmoja laskelmia siitä, kuinka paljon maataloudessa käytetään perheen jäsenten työtä, palkattua tai palkkaamatonta (siv. 31). Epäilemättä tällainen laskelma onkin summittainen. Varminta olisi kuitenkin ollut, että olisi laskettu tulokset molemmilla tavoilla ja vertailtu niitä keskenään. Tämä olisi tietenkin aiheuttanut lisää työtä, jota tri Lindbergin laaja ja arvokas tutkimus on jo tällaisenaankin vaatinut erittäin paljon. Kuten jo aikaisemmin sanoin, hyväksyn tri Lindbergin käyttämän reaalimenetelmän, mutta olen sitä mieltä, että menetelmää sovellettaessa on sattunut virheitä.

${ }^{1}$ LaUr, E., Grundlagen und Methoden der Bewertung, Buchhaltung und Kalkulationen in der Landwirtschaft. 3 Aufl., siv. 115.

${ }^{2}$ Tutkimuksia Suomen maatalouden kannattavaisuudesta (Maataloushallitus).

${ }^{3}$ K. U. Pinkala, Hintakomitean laskelmat v. 1944 ja Maatalous 1945, N:o 2, siv. 35. 
On syytä tässä ensin lähemmin selostaa eräitä tri Lindbergin esittämiä määritelmiä ja menetelmiä, jotka antavat selvän kuvan siitä, mihin hän on tutkimuksessaan pyrkinyt.

Tulon määritelmän hän on esittänyt seuraavasti: »Tulo on niiden hyödykkeiden summa (hyödykkeiden summan arvo), joka kertyy tietylle taloussubjektille tietyn ajan kuluessa ja on tämän subjektin käytettävänä tarpeiden tyydyttämiseksi, edellyttäen suunnitelmallista taloudellista toimintaa taloussubjektir taholta.» Maatalouden ja sen sivuelinkeinojen kokonaistuottoa laskettaessa tri Lindberg on laskenut kasvinviljelyn kokonaistuottoa määrittäessään sadon määrät ja arvot ottaen perustaksi maataloustilaston viralliset sato- ja pinta-alatiedot vuosilta 1926-1938, tehden niihin kuitenkin eräitä välttämättömiä oikaisuja. Paitsi pellon tuottoa, johon sisältyy myös niitystä saatu tuotto, on laskettu kasvitarhaviljelyn tuotto, myyntituottoisen puutarhaviljelyn tuotto ja metsämarjojen tuotto. Ensi silmäykseltä kasvinviljelyn tuotto näyttää erittäin tarkasti lasketulta, siinä kun esim. sellainenkin monen mielestä vähäarvoinen erä kuin metsämarjojen tuotto ja juurikasvien naatit on laskettu mukaan. Mutta laidunmaita ja niistä saatua tuottoa ei ole otettu huomioon (s. 53 ja 56). Laiduntuoton pois jättämistä ei ole millään tavalla perusteltu; on vain tultu yksinkertaisesti tällaiseen tulokseen. Seurattaessa tri Lindbergin teoksessaan esittämiä teoreettisia selvittelyjä tullaan selvästi siihen tulokseen, että laidunrehuyksiköt olisi ollut otettava mukaan. Miksei niitä yhtä hyvin oteta satona huomioon kuin esim. metsämarjojen satoa? Nehän ovat epäilemättä hyödykkeitä nekin, hyödykkeitä, jotka ovat kertyneet tietylle taloussubjektille tietyn ajan kuluessa. Niinikään ne ovat olleet tämän subjektin käytettävänä tarpeiden tyydyttämiseksi. Laitumen pois jättämistä voitaisiin jotenkin perustella nettolaskelmassa sillä, että laidunrehuyksiköt tulevat vähennettäviksi tuotosta, joka saadaan karjataloudesta. Mutta samoinhan on esim. olkien ja juurikasvien naattien laita, joiden rehuyksikköarvo on otettu mukaan (s. 35). On ilman muuta selvää, että laidunrehuyksiköt on otettava huomioon kasvinviljelyn kokonaistuottoa määritettäessä ja sitten taas vähennyksissä karjatalouden tuottoa laskettaessa. Laidunrehuyksiköiden pois jättäminen tuntuu sitäkin merkillisemmältä, kun tässä ei ole kysymyksessä mitkään pienet summat, vaan sangen valtavat sekä rehuyksikkömäärät että niiden raha-arvot. Mielestäni olisi kyllä voinut jättää pois sellaiset kuin naatit ja oljetkin ja käyttää vanhaa laskutapaa, jossa oljet peltoviljelypuolella ja lanta karjatalouspuolella pannaan vastakkain, mutta menetelmää, että laidunrehuyksiköt ilman muuta jätetään maataloustuotosta pois, ei voida hyväksyä. Olen seuraavassa laskenut laidunrehuyksiköiden määrän käyttäen perustana tilastosta saatuja vuotuisia kotieläinmääriä ja lukuja, jotka osoittavat, paljonko eri kotieläimet keskimäärin kesän aikana käyttävät laidunrehuyksiköitä. Lypsylehmien käyttämäksi laidunrehuyksikkömääräksi on otettu vuosittain karjantarkastuskirjanpidosta saadut luvut. Hevosten, nuorenkarjan, lampaiden, vuohien ja porojen kohdalla on käytetty valtion laidunkoeasemalla tutkimusten tuloksina saatuja lukuja. Lehmien ja sonnien keskimäärin vuosittain käyttämä laidunrehuyksiköiden määrä on täten eri vuosina vaihdellut 483 ja 696 ry:n välillä, hevosten vuotuinen ry-määrä on laskettu 960 
ry:ksi, nuorten hevosten ja varsojen 600 ry:ksi, nuorten sonnien ja hiehojen 525 ry:ksi, vasikoiden (alle 1 v.) 180 ry:ksi sekä lampaiden, vuohien ja porojen 117 ry:ksi.

Kaikkien kotieläinten laitumilta yhteensä saama ry-määrä.

\begin{tabular}{|c|c|c|c|c|c|}
\hline Vuosi & & ry.-määrä & Vuosi & & ry.-määrä \\
\hline 1926 & & 1.359 .924 .099 & 1933 & & 1.493 .387 .856 \\
\hline 1927 & & 1.383 .218 .817 & 1934 & . & 1.453 .071 .369 \\
\hline 1928 & & 1.409 .265 .355 & 1935 & & 1.517 .493 .506 \\
\hline 1929 & & 1.381 .087 .918 & 1936 & & 1.573 .749 .381 \\
\hline 1930 & & 1.425 .095 .076 & 1937 & . & 1.606 .627 .433 \\
\hline 1931 & $\ldots$ & 1.489 .521 .342 & 1938 & $\ldots \ldots \ldots$ & 1.613 .870 .163 \\
\hline 1932 & $\ldots \ldots \ldots$ & 1.463 .493 .085 & & & \\
\hline
\end{tabular}

Laidunrehuyksiköiden määrä on jotenkin samaa tasoa kuin kaikkien viljakasvien yhteinen rehuyksikkömäärä. Kasvinviljelyn tuottama hyödykkeiden määrä lisääntyy siis näin valtavalla ry-määrällä. Jos lasketaan laidun-ry:n raha-arvoksi $1 \mathrm{mk}$, päädytään noin puolentoista miljardin markan suuruiseen summaan. Jotta saataisiin oikea tulos kasvinviljelyn kokonaistuottoa laskettaessa, on tri Lindbergin esittämiin lukuihin lisättävä nämä pois jääneiden laidunrehuyksiköiden arvot. Tähän voidaan huomauttaa, mitä tällaisesta laskelmasta lopullisesti on hyötyä, kun tämä noin 1,5 miljardin summa on käytetty karjalle ja karjatalouden kokonaistuottoa laskettaessa sama summa on taas vähennettävä oikeaan tulokseen pääsemiseksi. Jos näin menetellään, tulee karjatalous, joka tri Lindbergin laskelmien mukaan jo sinänsä on tuottanut heikosti, vielä epäedullisemmaksi. Tässä on kuitenkin otettava huomioon, että niin tarkkaa työtä kuin karjatalouslaskelmassa on yritettykin tehdä, on siinäkin pääosaltaan jäänyt pois eräs sangen huomattava erä, nimittäin hevostalouden tuotto. Tähän tietysti voidaan sanoa, että hevostalouden tuottoa on tarpeeton laskea, koska lähes sama erä, joka tuottona on kotieläinpuolella, on kasvinviljelyssä laskettava kustannuksena. Samoin on kotieläintuottoa laskettaessa jäänyt huomioon ottamatta lannan arvo, joka sekin on karjatalouden kokonaistuottoa laskettaessa otettava huomioon. Tässäkin tietysti voitaisiin samoin sanoa olevan turhaa ottaa lannan arvoa karjataloudessa huomioon, sillä sama erähän on sitten menona kasvinviljelypuolella, ja maatalouden kokonaistulos pysyy samana, otettiinpa tuo luku huomioon taikka ei. Niin asian laita tietysti onkin maatalouden tuottoon nähden kokonaisuudessaan, mutta ei suinkaan kotieläintuottoa laskettaessa. Tulos ei ole oikea, jos hevostalouden tuotto ja lanta jätetään huomioon ottamatta. Jos tahdotaan esittää, kuten julkaisussa on tehty, kotieläintalouden kokonaistuotto, se on tehtävä niin kuin tri Lindberg muita taloushaaroja käsitellessään on menetellyt; toisin sanoen talouksien tuotot on arvioitava kokonaisuudessaan ja sen jälkeen tehtävä tarpeelliset vähennykset. Olen koettanut seuraavassa taulukossa laskea hevostyön tuoton pitäen perustana maatalouslaskennoissa selvitettyjä hevosmääriä ja niitä lukuja, jotka maatalouden kannattavaisuustutkimuksen mukaan osoittavat, montako työpäivää hevoset vuodessa suorittavat. Tulos on seuraava: 


\begin{tabular}{cccccc} 
Vuosi & \multicolumn{2}{c}{$\begin{array}{c}\text { Työhevosia } \\
\text { kpl. }\end{array}$} & $\begin{array}{c}\text { Työpäiviä } \\
\text { vuodessa }\end{array}$ & $\begin{array}{c}\text { Päivätyön } \\
\text { arvo mk }\end{array}$ & $\begin{array}{c}\text { Hevostyön tuotto } \\
\text { milj. mk }\end{array}$ \\
1926 & $\ldots \ldots \ldots \ldots$ & 334.912 & 141 & 30 & 1417 \\
1927 & $\ldots \ldots \ldots \ldots$ & 335.409 & 145 & 30 & 1459 \\
1928 & $\ldots \ldots \ldots \ldots$ & 335.313 & 143 & 32 & 1534 \\
1929 & $\ldots \ldots \ldots \ldots$ & 329.662 & 137 & 30 & 1355 \\
1930 & $\ldots \ldots \ldots \ldots$ & 325.902 & 147 & 27 & 1294 \\
1931 & $\ldots \ldots \ldots \ldots$ & 326.230 & 142 & 23 & 1065 \\
1932 & $\ldots \ldots \ldots \ldots$ & 324.737 & 142 & 22 & 1015 \\
1933 & $\ldots \ldots \ldots \ldots$ & 320.949 & 147 & 23 & 1095 \\
1934 & $\ldots \ldots \ldots \ldots$ & 319.385 & 149 & 23 & 1158 \\
1935 & $\ldots \ldots \ldots \ldots$ & 317.376 & 152 & 24 & 1253 \\
1936 & $\ldots \ldots \ldots \ldots$ & 315.633 & 147 & 27 & 1548 \\
1937 & $\ldots \ldots \ldots \ldots$ & 316.416 & 146 & 32 & \\
1938 & $\ldots \ldots \ldots \ldots$ & 320.530 & 138 & 35 &
\end{tabular}

Hevospäivätyön arvoksi olen ottanut saman luvun, joka maatalouden kannattavaisuustutkimuksissa kunakin vuonna osoittaa miehen päivätyön arvoa, koska yleensä käytännössä pidetään mies- ja hevospäivätyötä samanarvoisina. Hevostyön arvo on täten tullut suunnilleen oikein lasketuksi. Hevostyön arvosta on vähennettävä se osa, joka on käytetty juokseviin maataloustöihin, kun taas perusparannuksiin ja moniin kuljetus- ym. töihin maataloudessa käytetty osa on laskettava kansantuloksi. Jotta tämä voitaisiin riittävän täsmällisesti määrittää, olisi suoritettava tarkempia laskelmia. Olen arvioinut varsinaisen maatalouden ulkopuolelle jäävän osan kolmannekseksi koko hevostyön arvosta. Tri Lindberg on laskenut metsätalouden tuloon myös puutavaran ajon kuljetusreittien varrelle, ja tämä ajohan suoritetaan suurimmalta osaltaan hevosilla. Jos nyt hevostyön arvoksi otetaan edellämainitut summat, niin tässä tulee kaksinkertaisena se kansantaloudellinen tulo, jonka hevoset ovat metsätöissä suorittaneet. On ilman muuta selvää, että hevosten työ ei ole mitään metsätuloa, vaan se olisi ollut erotettava metsätulostá ja laskettava maatalouspuolelle, jos tahdotaan tehdä laskelmat teoreettisesti oikein. Pidettäessä päämääränä vain oikeaa kansantaloudellista tuloa kokonaisuudessaan ei tässä tietenkään tule virhettä, vaikka jokin osa tuloista laskettaisiinkin toisen tilille.

Rakennustoiminnassa esiintyvä kansantaloudellinen tulo on otettu huomioon omana ryhmänään. Maataloudessa esiintyy sangen paljon rakennustoimintaa, jonka maatalousväki itse suorittaa. Voitaisiin ajatella, että olisi menetelty oikeammin laskemalla tämä rakennustoiminta, jonka maatalousväki omalla väellä omilla tiloillaan suorittaa, maatalouteen kuuluvaksi. Mutta hyvin voi kyllä ymmärtää ja hyväksyä sellaisenkin menetelmän, jota tri Lindberg on käyttänyt.

Saman arvoista työtä kuin rakennustoiminta ja tietyöt, jotka molemmat on kansantaloudellista tuloa laskettaessa otettu huomioon, ovat mielestäni uudisviljelys ja perusparannustyöt. Kysessäolevana aikana on Suomessa suoritettu valtava uudisviljelystyö, ei ainoastaan tekemällä huomattavasti uutta peltoa, vaan myös siten, että vanhoja peltoja on paljon kunnostettu, tehty viljelysteitä ja suoritettu muitakin perusparannuksia, mm. salaojituksia. Nämä olisi pitänyt ottaa 
huomioon kansantuloa laskettaessa, ja ne kuuluvat epäilemättä maataloudesta saatuun kansantuloon. Seuraavassa esitetään taulukko, kuinka paljon uudisviljelystöitä kyseessäolevana aikana Suomessa on suoritettu.

\begin{tabular}{ccccc} 
Vuosi & \multicolumn{2}{c}{$\begin{array}{c}\text { Uudisvilje- } \\
\text { lystä ha }\end{array}$} & $\begin{array}{c}\text { Arvo } \\
\text { mk/ha }\end{array}$ & $\begin{array}{c}\text { Yhteensä } \\
\text { milj. mk }\end{array}$ \\
1926 & $\ldots \ldots \ldots \ldots$ & 50.000 & 8975 & 449 \\
1927 & $\ldots \ldots \ldots \ldots$ & 50.000 & 9732 & 487 \\
1928 & $\ldots \ldots \ldots \ldots$ & 50.000 & 10586 & 529 \\
1929 & $\ldots \ldots \ldots \ldots$ & 51.434 & 10920 & 562 \\
1930 & $\ldots \ldots \ldots \ldots$ & 51.434 & 10867 & 559 \\
1931 & $\ldots \ldots \ldots \ldots$ & 43.719 & 10561 & 462 \\
1932 & $\ldots \ldots \ldots \ldots$ & 49.151 & 10370 & 510 \\
1933 & $\ldots \ldots \ldots \ldots$ & 43.117 & 10148 & 438 \\
1934 & $\ldots \ldots \ldots \ldots$ & 52.060 & 10106 & 526 \\
1935 & $\ldots \ldots \ldots \ldots$ & 47.521 & 10049 & 478 \\
1936 & $\ldots \ldots \ldots \ldots$ & 38.250 & 10349 & 396 \\
1937 & $\ldots \ldots \ldots \ldots$ & 23.481 & 10827 & 254 \\
1938 & $\ldots \ldots \ldots \ldots$ & 31.061 & 11486 & 357
\end{tabular}

On kovin vaikea arvioida, kuinka suureksi tämä uudisviljelyksestä saatu kansantulo on laskettava, mutta arvio ei voi tulla liian suureksi, jos hehtaarin raivaus- ja muiden pääomien sijoitusarvoksi otetaan sama arvo, joka kirjanpidossa on laskettu kunakin vuonna maatalouspääomien yhteiseksi arvoksi. (Nythän tämä arvo on huomattavasti suurempi.)

Jos lopuksi laskemme, millaiseksi maatalouden kansantaloudellinen tulo muodostuu näiden korjausten jälkeen, saamme tulokseksi seuraavan:

\begin{tabular}{|c|c|c|c|c|c|c|c|}
\hline Vuosi & & $\begin{array}{l}\text { Tri Lind- } \\
\text { bergin muk. } \\
\text { bruttotuotto }\end{array}$ & $\begin{array}{l}\text { Laitumelta } \\
\text { saadun re- } \\
\text { hun arvo }\end{array}$ & $\begin{array}{c}\text { Hevostyön } \\
\text { arvo }\end{array}$ & $\begin{array}{l}\text { Lannan } \\
\text { arvo }\end{array}$ & $\begin{array}{l}\text { Uudis- } \\
\text { viljelyksen } \\
\text { arvo }\end{array}$ & $\begin{array}{c}\text { Maatalouden } \\
\text { bruttotuotto } \\
\text { yhteensä }\end{array}$ \\
\hline 1926 & $\ldots \ldots \ldots$ & 9.332 & 1360 & 1417 & 105 & 449 & 12.663 \\
\hline 1927 & $\ldots \ldots \ldots$ & 9.589 & 1383 & 1459 & 93 & 487 & 13.011 \\
\hline 1928 & $\ldots \ldots \ldots$ & 9.299 & 1409 & 1534 & 74 & 529 & 12.845 \\
\hline 1929 & $\ldots \ldots \ldots$ & 8.294 & 1381 & 1355 & 73 & 562 & 11.665 \\
\hline 1930 & $\ldots \ldots \ldots$ & $8 \cdot 182$ & 1425 & 1294 & 85 & 559 & 11.545 \\
\hline 1931 & $\ldots \ldots \ldots$ & 7.677 & 1490 & 1065 & 81 & 462 & 10.775 \\
\hline 1932 & $\ldots \ldots \ldots$ & 7.948 & 1463 & 1015 & 78 & 510 & 11.014 \\
\hline 1933 & $\ldots \ldots \ldots$ & $8 \cdot 402$ & 1493 & 1085 & 115 & 438 & 11.533 \\
\hline 1934 & $\ldots \ldots \ldots$ & 8.643 & 1453 & 1095 & 96 & 526 & 11.813 \\
\hline 1935 & $\ldots \ldots \ldots$ & 8.875 & 1517 & 1158 & 79 & 478 & 12.107 \\
\hline 1936 & $\ldots \ldots \ldots$ & 10.149 & 1574 & 1253 & 78 & 396 & 13.450 \\
\hline 1937 & $\ldots \ldots \ldots$ & 12.272 & 1607 & 1478 & 157 & 254 & 15.768 \\
\hline 1938 & $\ldots \ldots \ldots$ & . $\quad 11.928$ & 1614 & 1548 & 94 & 357 & 15.541 \\
\hline
\end{tabular}

Tätä taulukkoa esitettäessä on huomattava, että se on tehty jossakin määrin ylimalkaisesti yleisen tilaston perusteella eikä siinä joka kohdassa ole noudatettu riittävää perinpohjaisuutta. Mutta tällaisenakin se jo osoittaa, missä kohden 
olisi pitänyt tehdä korjauksia. Tämän jälkeen suoritetaan vastaavanlainen korjauslaskelma vähennyksien puolella:

V ähennykset milj. m k

\begin{tabular}{|c|c|c|c|c|c|}
\hline Vuosi & $\begin{array}{l}\text { Lisäys kotiel. } \\
\text { ruokintaan. } \\
\text { Laidun }\end{array}$ & $\begin{array}{c}\text { Kotoinen } \\
\text { lanta }\end{array}$ & $\begin{array}{l}\text { Hevostyön } \\
\text { arvo maa- } \\
\text { taloudessa }\end{array}$ & $\begin{array}{l}\text { Vähennykset } \\
\text { tri Lind- } \\
\text { bergin muk. }\end{array}$ & $\begin{array}{c}\text { Vähennykset } \\
\text { yhteensä }\end{array}$ \\
\hline 1926 & $\ldots \ldots \ldots \ldots$ & 105 & 944 & 5201 & 7610 \\
\hline 1927 & $\ldots \ldots \ldots \ldots$ & 93 & 972 & 5163 & 7611 \\
\hline 1928 & $\ldots \ldots \ldots \ldots$ & 74 & 1022 & 5060 & 7565 \\
\hline 1929 & $\ldots \ldots \ldots \ldots$ & 73 & 902 & 4365 & 6721 \\
\hline 1930 & $\ldots \ldots \ldots$ & 85 & 862 & 4407 & 6779 \\
\hline 1931 & $\ldots \ldots \ldots$ & 81 & 710 & 4293 & 6574 \\
\hline 1932 & $\ldots \ldots \ldots \ldots$ & 78 & 676 & 4271 & 6488 \\
\hline 1933 & $\ldots \ldots \ldots \ldots$ & 115 & 722 & 4736 & 7066 \\
\hline 1934 & $\ldots \ldots \ldots \ldots$ & 96 & 730 & 4541 & 6820 \\
\hline 1935 & $\ldots \ldots \ldots \ldots$ & 79 & 772 & 4450 & 6818 \\
\hline 1936 & $\ldots \ldots \ldots \ldots$ & 78 & 836 & 5285 & 7773 \\
\hline 1937 & $16 \circ 7$ & 157 & 986 & 6700 & 9450 \\
\hline 1938 & $\ldots \ldots \ldots \ldots$ & 94 & 1032 & 6198 & 8938 \\
\hline
\end{tabular}

Yhdistelmä, jossa on laskettu kokonaistuoton ja vähennysten ero, muodostuu täten seuraavaksi:

\section{YHDISTELMÄ.}

$\mathrm{Milj} . \mathrm{m} \mathrm{k}$

$\begin{array}{ccccc}\text { Vuosi } & & \begin{array}{c}\text { Brutto- } \\ \text { tuotto }\end{array} & \begin{array}{c}\text { Vähennys- } \\ \text { erät }\end{array} & \begin{array}{c}\text { Erotus (kan- } \\ \text { santulo maa- } \\ \text { taloudesta) }\end{array} \\ 1926 & \ldots \ldots \ldots \ldots & 12.663 & 7610 & 5053 \\ 1927 & \ldots \ldots \ldots \ldots & 19.011 & 7611 & 5400 \\ 1928 & \ldots \ldots \ldots \ldots & 12.845 & 7565 & 5280 \\ 1929 & \ldots \ldots \ldots \ldots & 11.665 & 6721 & 4944 \\ 1930 & \ldots \ldots \ldots \ldots & 11.545 & 6779 & 4766 \\ 1931 & \ldots \ldots \ldots \ldots & 10.775 & 6574 & 4201 \\ 1932 & \ldots \ldots \ldots \ldots & 11.014 & 6488 & 4526 \\ 1933 & \ldots \ldots \ldots \ldots & 11.533 & 7066 & 4467 \\ 1934 & \ldots \ldots \ldots \ldots & 11.813 & 6820 & 4993 \\ 1935 & \ldots \ldots \ldots \ldots & 12.107 & 6818 & 5289 \\ 1936 & \ldots \ldots \ldots \ldots & 13.450 & 7773 & 5677 \\ 1937 & \ldots \ldots \ldots \ldots & 15.786 & 9450 & 6318 \\ 1938 & \ldots \ldots \ldots \ldots & 15.541 & 8938 & 6603\end{array}$

Kun edellä esitetyn perusteella arvostellaan tri Lindbergin teosta, päädytään siihen tulokseen maatalouden kannalta, että siinä koko kansantuloa laskettaessa käytetyt periaatteet ovat oikeat. Tutkimuksessa on tehty tälläkin kohdalla sangen suuri ja arvokas työ. Mutta vaikka myönnetäänkin maatalouden osalta käytetyt menetelmät oikeiksi, niitä ei ole käytännössä toteutettu oikein. On ikäänkuin riisuttu osa maatalouden tuloa pois. Metsässä suoritetut hevosajot on laskettu metsätalouteen, maataloudessa omallakin väellä suoritettu rakennustyö on laskettu rakennustoimintaan, suuret erät uudisraivaus- ja perusparannustyötä sekä laitu- 
melta saatavat rehuyksiköt on jätetty kokonaan pois, samoin kotieläintalouden kokonaistuottoa laskettaessa on jätetty pois hevostyön ja lannan arvo. Jos tri Lindberg olisi käyttänyt tarkistuslaskelmana prof. LAURIn edellä esitettyä menetelmää, olisi reaalimenetelmää käyttäen laskettu maatalouden kansantaloudellinen tulo epäilemättä tullut oikeammin lasketuksi.

\section{REFERAT.}

DAS LANDWIRTSCHAFTLICHE EINKOMMEN IN DER UNTERSUCHUNG ASUMEN KANSANTULO v. 1926-38; (DAS VOLKSEINKOMMEN FINNLANDS i. d. J. 1926-38) von Dr. VALTER LINDBERG.

Rurik Pihkala.

Der Aufsatz enthält eine Kritik von Dr. W. LindBergs Untersucbnng, die das Volkseinkommen Finnlands in den Jahren 1926 - 38 behandelt. Der Kritiker ist der Ansicht, dass bei Berechnung des Volkseinkommens aus der Landwirtschaft zu dem Ertrag des Pflanzenanbaues auch der von der Weide erhaltene Futtermittelwert zu zahlen sei, ebenso zu dem Ertrag der Haustierwirtschaft der Wert der Pferdearbeit und des Düngers sowie zum Arbeitsertrag auch Urbarmarhung und Bauarbeit der Landwirtschaft. Von diesen Ertragsposten erscheinen bei Berechnung des Volkseinkommens zwar der Ertrag der Weide als Abzug in der Haustierwirtschaft sowie der Düngerwert und ein Teil der Pferdearbeit als Abzüge beim Pflanzenanbau, dagegen vermehren der Wert der nicht zu den fortlaufenden Landwirtschaftsarbeiten gehörenden Prerdearbeit und der Wert der Urbarmachung das Volkseinkommen. 